RASĀYAN J. Chem.

Vol. 14 | No. 2 |836-843| April - June | 2021 ISSN: 0974-1496 | e-ISSN: 0976-0083 | CODEN: RJCABP http://www.rasayanjournal.com http://www.rasayanjournal.co.in

\title{
PROCESS FOR REDUCING THE MAGNESIUM CONTENT IN INDUSTRIAL PHOSPHORIC ACID BY ITS PRECIPITATION TO MAGNESIUM FLUOROSILICATE
}

\author{
A. Boukhsib ${ }^{1, \bowtie}$, L. Khamar ${ }^{1}$, M. S. Kadiri ${ }^{1}$ and L. Omari ${ }^{2}$ \\ ${ }^{1}$ IPIM Laboratory, ENSAK, University Sultan Moulay Slimane, Beni Mellal-23591, Morocco \\ ${ }^{2}$ Direction Innovation, OCP Group, Jorf Lasfar-24118, Morocco \\ ${ }^{\square}$ Corresponding Author: a.boukhsib@gmail.com
}

\begin{abstract}
The major inconvenience of wet phosphoric acid (PA) process is the production of PA profiles containing a large matrix of dissolved impurities, especially the magnesium $(\mathrm{MgO})$. This is one of the undesirable impurities that penalize the performances and monitoring of this process kind. Indeed, it contributes to the increase of the viscosity of the phosphoric acid and to the decrease of the crystalline growth kinetics of gypsum phase in the reactional medium. In addition, this impurity contributes to the formation of insoluble complex mineral phases, which subsequently lead to fouling problems and significant phosphorus losses. In this work, we evaluated experimentally the performance of a new method for its removal from a phosphoric acid profile with a phosphorus content of $29 \% \mathrm{P}_{2} \mathrm{O}_{5}$. These are in fact the chemical precipitation of magnesium using fluosilicic acid and acetone. This method also aims to inhibit the undesirable effects of magnesium on the operations of its concentration and on the downstream fertilizer manufacturing processes. The obtained results show an efficiency of removal of $\mathrm{MgO}$ of about $85 \%$ with negligible losses of phosphorus.
\end{abstract}

Keywords: Phosphoric acid, Magnesium, Precipitation, Fluosilicic acid, Acetone, Magnesium fluorosilicate

RASĀYAN J. Chem., Vol. 14, No.2, 2021

\section{INTRODUCTION}

Industrial phosphoric acid (PA) is produced mainly from sedimentary phosphate rock. ${ }^{1,2} 90 \%$ of its industrial production is carried out by wet processes. ${ }^{3,4}$ It is the second most important mineral acid produced in the world after sulphuric acid, which is the acid mainly used as an intermediate product in the leaching of mineral phosphates. At the industrial level, PA is widely used as a raw material or intermediate product in many industries, such as the production of detergents, food products and animal feed, and toothpaste. However, it is widely used in the manufacture of fertilizers. ${ }^{1,2}$ It contains highly variable amounts of impurities that depend on the quality of the phosphate rock being recovered. ${ }^{1,5}$ It has long been recognized, that some of these impurities can cause many problems in the manufacture of phosphoric acid by wet process. ${ }^{6}$ Among these, we find the magnesium; its content in the commercial phosphate profiles is about $0.2 \%$ to $0.6 \% \mathrm{MgO}$. Nevertheless, in the dolomitic phosphate rocks, these contents are higher than $2 \% \mathrm{P}_{2} \mathrm{O}_{5}{ }^{1}$

The magnesium is extremely troublesome impurity for higher content. This impurity affects the entire phosphoric acid and fertilizer manufacturing chain. ${ }^{3}$ The high magnesium content leads to a drop in the filtration capacity and to a decrease in the chemical yield during the manufacturing of phosphoric acid. ${ }^{7,8}$ The analysis of the apparent viscosity of both $\mathrm{PA} 29 \% \mathrm{P}_{2} \mathrm{O}_{5}$ and $\mathrm{PA} 54 \% \mathrm{P}_{2} \mathrm{O}_{5}$ produced by concentration, show that this rheological parameter increases with increasing of $\mathrm{MgO}$ content. However, the influence of $\mathrm{MgO}$ is very important on the viscosity of the PA $54 \% \mathrm{P}_{2} \mathrm{O}_{5}$ produced. ${ }^{8}$ The presence of magnesium is also responsible for the formation of sludge following post-precipitation by desupersaturation of some impurities such as Ralsonite $\left(\mathrm{MgAlF}_{6} \cdot 6 \mathrm{H}_{2} \mathrm{O}\right), \mathrm{MgSO}_{4}$, and $\mathrm{MgSiF}_{6}$ causing the formation of deposit solids and sludge in the reactors, storage tanks and the pipes of the industrial facilities. These sludges exhibit significant losses of $\mathrm{P}_{2} \mathrm{O}_{5},{ }^{9}, 10$ In addition, magnesium has negative impacts not only on the quality of 
RASĀYAN J. Chem.

Vol. 14 | No. 2 |836-843| April - June | 2021

phosphate fertilizers such as di-ammonium phosphate (DAP) by formation of the mineral phase $\mathrm{MgNH}_{4} \mathrm{PO}_{4}$, but also on the processes of their industrial manufacturing. ${ }^{10,11}$

In the current context marked by the exhaustion of very good quality mines and the increase in the world population, the phosphate industries will have to use more and more phosphates of lower quality with more and more high of $\mathrm{MgO}$ contents. It is therefore important to seek methods, which allow its elimination or reduction. Generally, the various methods currently used to purify phosphoric acid produced from wet process include among others, adsorption, flotation, ion exchange, electrodialysis, electrode ionization, liquid-liquid extraction as well as chemical precipitation. Adsorption is a technique used mainly for the removal of organic matter present in phosphoric acid, for compounds with an ionic character such as magnesium are more difficult to be adsorbed, the adsorption efficiency is always low. ${ }^{12}$ The application of flotation and ion exchange resin to industrial phosphoric acid is poor, because the removal efficiency is often low. ${ }^{13,14}$ Electrodialysis in general requires a very dilute phosphoric acid and a long residence time with a good choice of membrane and the performances recorded remain low. ${ }^{15}$ Ion exchange resins show their limits, in that even when combined with a different form of electrodialysis: Electrode-ionization, the purification performance for Magnesium remains low at around 30\%. ${ }^{16}$

The liquid-liquid extraction applied for the selective removal of magnesium results in an acid containing as little $\mathrm{MgO}$ as possible. However, it involves high investment and operating costs and requires more careful handling and the choice of an appropriate solvent is a problem. This technique is widely used rather for $\mathrm{P}_{2} \mathrm{O}_{5}$ extraction to produce food grade phosphoric acid, but it requires having concentrated and pretreated phosphoric acid. ${ }^{17,18}$ Chemical precipitation appears to be the natural method for removing Magnesium from phosphoric acid: the ideal conditions are created for Magnesium to complex and precipitate with other cations and anions present in the medium. In phosphoric acid prepared by the dihydrate process, Magnesium is found in ionic form: $\mathrm{Mg}^{2+}$, which precipitates either in crystalline solid or in viscous solid, many experts have proposed methods and processes allowing to control this precipitation by precipitating as much magnesium as possible while reducing the losses of $\mathrm{P}_{2} \mathrm{O}_{5}$ in phosphoric acid.

Several patents state the most important processes, which allow the precipitation of magnesium. Moore et al. ${ }^{19}$ have proposed process which consist in hydrolyzing the forms of fluorine present in the acid. The objective is to obtain a Magnesium-Aluminum-Fluorine complex. Indeed, to be able to combine with the metal cations, the Fluorine must be present in the form $\mathrm{HF}$ or $\mathrm{F}^{-}$, but it is initially present in the acid in the form of $\mathrm{SiF}_{4}$ or $\mathrm{H}_{2} \mathrm{SiF}_{6}$, in combination with atoms of Silicon. One method of removing silicon and returning the free form of fluorine is the controlled evaporation of part of the acid, proposed by Moore et al. When the level of $\mathrm{P}_{2} \mathrm{O}_{5}$ approaches $47-51 \%$, the level of silicon in the acid becomes low and the amount of $\mathrm{HF}$ present is much greater than that of the compounds $\mathrm{H}_{2} \mathrm{SiF}_{6}$ and $\mathrm{SiF}_{4}$.

In Patent No. US3379501A, Bunin Donald S and Leo Treitler Theodore have invented a process which aims to directly add compounds in free fluorine (HF) to purify a phosphoric acid from $10 \%$ to $30 \%$ in $\mathrm{P}_{2} \mathrm{O}_{5}{ }^{20}{ }^{2} \mathrm{It}$ is first necessary to adjust the level of calcium ions in the solution of phosphoric acid to a value between $0.25 \%$ and $3 \%$, by adding a calcium product (calcium carbonate). Then adding hydrofluoric acid in sufficient quantities of the order of about $5 \%$ by weight at room temperature, and the $\mathrm{pH}$ should be less than 2, preferably should be equal to 1.5 in order to avoid any loss of $\mathrm{P}_{2} \mathrm{O}_{5}$. The precipitate formed is calcium fluoride with magnesium. This patent also presents a process for regenerating hydrofluoric acid from the precipitate formed.

In its patent No. US4136199, Harold E. Mills was developed a process for reducing the aluminum and magnesium content of industrial phosphoric acid profiles with $\mathrm{P}_{2} \mathrm{O}_{5}$ contents is comprised between $38 \%$ and $54 \% \mathrm{P}_{2} \mathrm{O}_{5}{ }^{21}$ It consists of adding a precipitant containing calcium and fluorine to these PA profiles. To ensure a sufficient $\mathrm{F} / \mathrm{Mg}$ molar ratio (from 3.8 to 5), the $\mathrm{F} / \mathrm{Ca}$ molar ratio is maintained approximatively at 2/1 .In order to form a precipitate containing magnesium and aluminum, the temperature is kept from 115 to $140^{\circ} \mathrm{F}$ over a period of 2 to 6 days. To accelerate the rate of precipitate formation, sulfuric acid is added in a stoichiometric amount relative to fluorine.

Kenneth L et al..$^{22}$, in their patent No. US4299804A showed that magnesium and aluminum can be removed from industrial PA by adding a fluoride ion donor compound like hydrofluoric acid and an aluminum donor compound like alum. With the objective of forming the crystalline compound $\mathrm{MgAl}_{2} \mathrm{~F}_{8}$, they set the $\mathrm{Al} / \mathrm{Mg}$ 
RASĀYAN J. Chem.

Vol. 14 | No. 2 |836-843| April - June | 2021

molar ratio to 2 and the F/Al molar ratio to 4 . The acid was then introduced into a crystallizer with the objective of obtaining large crystals that could be easily separated from the processed phosphoric acid.

In patent No. EP0195031A1, Hassine Ayedi et al. ${ }^{23}$ have invented a process that has several advantages over the patents presented above. It consists in adding, at a temperature between $50^{\circ} \mathrm{C}$ and $70^{\circ} \mathrm{C}$, an ammonium compound soluble in phosphoric acid with a $\mathrm{P}_{2} \mathrm{O}_{5}$ content of $25 \%$ to $35 \%$, in order to obtain an $\mathrm{NH} 4 / \mathrm{Mg}$ molar ratio in the medium of between 0.5 and 4 . To precipitate magnesium as an insoluble complex in the form $(\mathrm{NH} 4) \mathrm{x}(\mathrm{Mg}) \mathrm{y}(\mathrm{Al}) \mathrm{z}(\mathrm{F}, \mathrm{OH})_{6}$, a fluorine donor compound is added until a $\mathrm{F} / \mathrm{Mg}$ molar ratio of between 4 and 20 is obtained, and an aluminum donor compound is also added until an $\mathrm{Al} / \mathrm{Mg}$ molar ratio of between 0.8 and 2 is obtained. The complex formed is a crystalline product with large grain size, which is then easily separated by filtration and decantation.

The precipitation method was also exploited by a technique of salting out with acetone, which is a solvent miscible with acid. Indeed, some heavy metals can be precipitated by hydroxide, carbonate or sulphide ions. Among these precipitates, the least soluble is that of the sulphides. However, in an acidic medium, the solubility of these sulphides remains high, precisely where the acetone release technique promotes the precipitation of these ions in phosphoric acid. It should be noted that the choice of acetone as solvent is not limiting where other solvents from the group of alcohols and ketones can also be used. ${ }^{11}$

In the Patent No. US3819810A, D Goldstein has disclosed a process for purifying phosphoric acid. ${ }^{24}$ The wet acid is freed from substantial magnesium impurities by contacting the acid with a soluble hexafluorosilicate $\left(\mathrm{SiF}_{6}{ }^{2-}\right)$ thus forming a precipitate of magnesium hexafluorosilicate hydrate $\left(\mathrm{MgSiF}_{6}, 6 \mathrm{H}_{2} \mathrm{O}\right)$ which is then removed by filtration after washing with a fluosilicic acid to avoid dissolving the magnesium hexafluorosilicate.

John F et al..$^{25}$ developed another purification process (patent No. US3975178A). It consists in precipitating the essential metallic and fluorinated impurities in the form of metallic phosphates, solid aluminium and fluorine-based mineral phases by adding methanol and ammonia. These solid phases thus obtained are separated from the aqueous phase by simple filtration, while the methanol is removed from the acid produced by distillation operation.

In the Patent No. FR2629812A1, Frida Kabbaj presents a process for removing heavy metals, in particular cadmium, from phosphoric acid by wet process. ${ }^{26}$ The phosphoric acid to be treated is subjected, during a first step, to the action of a sulfur compound soluble in phosphoric acid. Then during a second step, to the action of a solvent organic miscible with phosphoric acid is chosen from the group which comprises in particular alcohols and ketones, the precipitate formed during the second stage being separated, by filtration, from the treated phosphoric acid. The object of this invention is therefore to apply this technique to the elimination of cadmium and other heavy metals ( $\mathrm{As}, \mathrm{Cu}, \mathrm{Pb}, \mathrm{Mg}, \mathrm{Tl}, \mathrm{Mn}, \mathrm{Ni}, \mathrm{Zn}$, etc.) from phosphoric acid from wet process, however the magnesium removal efficiency is so low $(7.7 \%)$.

The main objective of this work is to determine on a laboratory scale, the performance of a process for removing magnesium present in industrial phosphoric acid containing $29 \% \mathrm{P}_{2} \mathrm{O}_{5}$, to inhibit its impact during the subsequent stages of concentration and fertilizer manufacturing. This process has the same principle as those illustrated in the patents already cited. ${ }^{24-26} \mathrm{We}$ use fluosilicic acid $\left(\mathrm{H}_{2} \mathrm{SiF}_{6}\right)$ to precipitate magnesium in the form of hydrated magnesium fluorosilicate $\left(\mathrm{MgSiF}_{6} 6 \mathrm{H}_{2} \mathrm{O}\right)$, and to promote this precipitation we will use acetone, which decreases its solubility and promotes its precipitation. This process has several advantages over other processes; it can use fluosilicic acid which can be a by-product of the phosphoric acid concentration unit. When the phosphoric acid is concentrated, the evaporation of silica tetrafluoride $\left(\mathrm{SiF}_{4}\right)$ and hydrofluoric acid (HF) is observed. These molecules, if released into the atmosphere without control, can have a negative impact on the environment. If the $\mathrm{SiF}_{4}$ content is high, the discharges can form encrustations in the condensers and the cooling sections of the concentrator units. The capture of these products is done in absorption towers. In these towers, SiF4 and HF are absorbed in a solution of fluosilicic acid (FSA). ${ }^{27}$ This process also has the advantage of precipitating a single crystalline form, which is magnesium fluorosilicate, which is easily separable by filtration. To achieve this objective, we are going to carry out tests on a laboratory scale. To determine the impact of the quantity of fluosilicic acid and acetone on the performance of magnesium elimination present in a phosphoric acid $29 \% \mathrm{P}_{2} \mathrm{O}_{5}$ at a temperature of $60^{\circ} \mathrm{C}$, which is the temperature at the end of the production cycle. 
RASĀYAN J. Chem.

Vol. 14 | No. 2 |836-843| April - June | 2021

\section{Principle}

\section{EXPERIMENITAL}

The principle of these laboratory tests consists of adding fluosilicic acid $\left(\mathrm{H}_{2} \mathrm{SiF}_{6}\right)$ and acetone to phosphoric acid $29 \% \mathrm{P}_{2} \mathrm{O}_{5}$ at the end of its production cycle after filtration operation, in the storage stage when the temperature decreases up to about $60^{\circ} \mathrm{C}$. Fluosilicic acid allows the precipitation of magnesium fluorosilicate according to the following reaction:

$$
\mathrm{SiF}_{6}^{2-}+\mathrm{Mg}^{2+}+6 \mathrm{H}_{2} \mathrm{O} \rightarrow \mathrm{MgSiF}_{6}, 6 \mathrm{H}_{2} \mathrm{O}
$$

The role of acetone is to reduce the solubility of magnesium fluorosilicate and therefore promotes its precipitation by release effect.

The main factors to study their impacts on precipitation performance are:

- The quantity of fluosilicic acid to be used, expressed in $\mathrm{SiF}_{6} / \mathrm{Mg}$ molar ratio.

- The specific amount of acetone to be used, expressed in gram Acetone/gram $\mathrm{P}_{2} \mathrm{O}_{5}$ existing in phosphoric acid

The amount of reagents used are varied at two levels, as presented in Table-1, which shows the experimental field.

Table-1: Experimental Domain of Precipitation by Addition of $\mathrm{H}_{2} \mathrm{SiF}_{6}$ and Acetone

\begin{tabular}{|c|c|c|}
\hline Factors & Number of Levels & Ratio \\
\hline \multirow{2}{*}{$\mathrm{SiF}_{6} / \mathrm{Mg}$} & \multirow{2}{*}{2} & 0.5 \\
\hline & & 1 \\
\hline \multirow{2}{*}{ gAcetone $/ \mathrm{gP}_{2} \mathrm{O}_{5}$} & \multirow{2}{*}{2} & 4 \\
\hline & & 8 \\
\hline
\end{tabular}

In order to optimize the number of experiments and facilitate the interpretation of the results, the experimental tests were undertaken by adopting a complete factorial design of experiments (see Table-2).

Table-2: Experimental Plan for Precipitation Tests by adding Acetone and $\mathrm{H}_{2} \mathrm{SiF}_{6}$

\begin{tabular}{c|c|c}
\hline Test $\mathrm{N}^{\circ}$ & $\mathrm{SiF}_{6} \mathrm{Mg}$ & gAcetone $/ \mathrm{gP}_{2} \mathrm{O}_{5}$ \\
\hline 1 & 0.5 & 8 \\
\hline 2 & 1 & 8 \\
\hline 3 & 0.5 & 4 \\
\hline 4 & 1 & 4 \\
\hline
\end{tabular}

\section{Materials and Reagents}

The products involved in this operating protocol are:

- Clear Industrial phosphoric profil containing $25.8 \% \mathrm{P}_{2} \mathrm{O}_{5}$ and $0.64 \% \mathrm{MgO}$.

- Fluosilicic acid diluted at $10 \%$, prepared from a stock solution of $35 \% \mathrm{H}_{2} \mathrm{SiF}_{6}$.

- Fluosilicic acid diluted to $20 \%$ (for washing the solid formed after its separation from the liquid phase).

- Acetone having a purity of $99.8 \%$

The equipment used to perform our magnesium precipitation tests are standard equipments of a laboratory. They consist of a heating plate with magnetic stirring equipped with a thermoregulator, to maintain the temperature fixed at $60^{\circ} \mathrm{C}$, filter crucibles for the separation of the solid formed by vacuum filtration and the usual laboratory glassware.

\section{Experimental Protocol}

Four experimental tests were undertaken in this study. In each test, we start by heating a sample of $400 \mathrm{ml}$ of acid to a temperature of $60^{\circ} \mathrm{C}$. Then, we successively introduce fluosilicic acid and acetone, according to the different weightings described by the factorial plan (see table-2). During each test, the agitation is kept constant. After about 15 minutes, complete solubilization is achieved. Subsequently, the first filtration of the reaction mixture is carried out in order to separate the liquid phase (acetone and phosphoric acid) and the solid phase. The solid thus obtained is washed with a $20 \%$ fluosilicic acid solution, then dried in an oven at a temperature of $60^{\circ} \mathrm{C}$. in order to be characterized by XRD.

The liquid phase is heated to remove the acetone and leave the phosphoric acid that will be sent for analysis of $\mathrm{P}_{2} \mathrm{O}_{5}$ and $\mathrm{MgO}$, these analyzes will allow us to measure the performance of these precipitation tests. In 
RASĀYAN J. Chem.

Vol. 14 | No. 2 |836-843| April - June | 2021

an industrial process, acetone, which is mixed with phosphoric acid, is distilled off and recovered for reuse as a reagent.

\section{RESULTS AND DISCUSSION}

To evaluate the magnesium precipitation performance, we calculated a $\mathrm{P}_{2} \mathrm{O}_{5}$ recovery efficiency and a magnesium removal efficiency for the different ratios of $\mathrm{H}_{2} \mathrm{SiF}_{6}$ and Acetone, based on the analyzes of $\mathrm{P}_{2} \mathrm{O}_{5}$ and $\mathrm{MgO}$ in the treated acid. The experimental results obtained are presented in Table- 3 .

Table-3: Experimental Results of Precipitation by Addition of $\mathrm{H}_{2} \mathrm{SiF}_{6}$ and Acetone

\begin{tabular}{c|c|c|c|c}
\multicolumn{5}{|c}{ Table-3: Experimental Results of Precipitation by Addition of $\mathrm{H}_{2} \mathrm{SiF}_{6}$ and Acetone } \\
\hline Test No. & $\mathrm{SiF}_{6} / \mathrm{Mg}$ & gAcetone/gP $\mathrm{O}_{5}$ & $\begin{array}{c}\text { Yield of } \mathrm{P}_{2} \mathrm{O}_{5} \\
\text { Recovery (\%) }\end{array}$ & $\begin{array}{c}\text { Yield of } \mathrm{MgO} \\
\text { Removal (\%) }\end{array}$ \\
\hline 1 & 0.5 & 8 & 96.41 & 67.5 \\
\hline 2 & 1 & 8 & 97.16 & 85.96 \\
\hline 3 & 0.5 & 4 & 96.35 & 2.9 \\
\hline 4 & 1 & 4 & 96.03 & 28.04 \\
\hline
\end{tabular}

It can be seen from Table- 3 that the recovery efficiency of $\mathrm{P}_{2} \mathrm{O}_{5}$ is interesting and it is almost stable for all the tests realized, it is between $96 \%$ and $97 \%$. This efficiency can be improved by reducing the losses of $\mathrm{P}_{2} \mathrm{O}_{5}$ which are mainly due to the entrainment of a part with the vapors during the concentration of the phosphoric acid-acetone mixture to separate the two phases, a strict control of the concentration conditions allows this reduction of losses. It is also possible to recover a part of $\mathrm{P}_{2} \mathrm{O}_{5}$ which remains soluble in the solid phase of magnesium fluorosilicate, and which is due to poor spinning, during the washing operation with fluosilicic acid diluted to $20 \%$ prepared from a stock solution of $35 \% \mathrm{H}_{2} \mathrm{SiF}_{6}$. The washing filtrate recovered is a fluosilicic acid containing the soluble $\mathrm{P}_{2} \mathrm{O}_{5}$, it can be diluted to $10 \% \mathrm{of}_{2} \mathrm{SiF}_{6}$ and recycled to precipitation reactor.

The $\mathrm{MgO}$ removal yield varies greatly between $2.9 \%$ and $86 \%$ depending on the amounts introduced of the reagents. A study based on a full factor analysis based on the recorded experimental results, allowed us to draw diagrams that show the effect of the $\mathrm{SiF}_{6} / \mathrm{Mg}$ molar ratio and the amount of acetone on the $\mathrm{P}_{2} \mathrm{O}_{5}$ recovery yield and on $\mathrm{MgO}$ removal yield (Fig.-1).
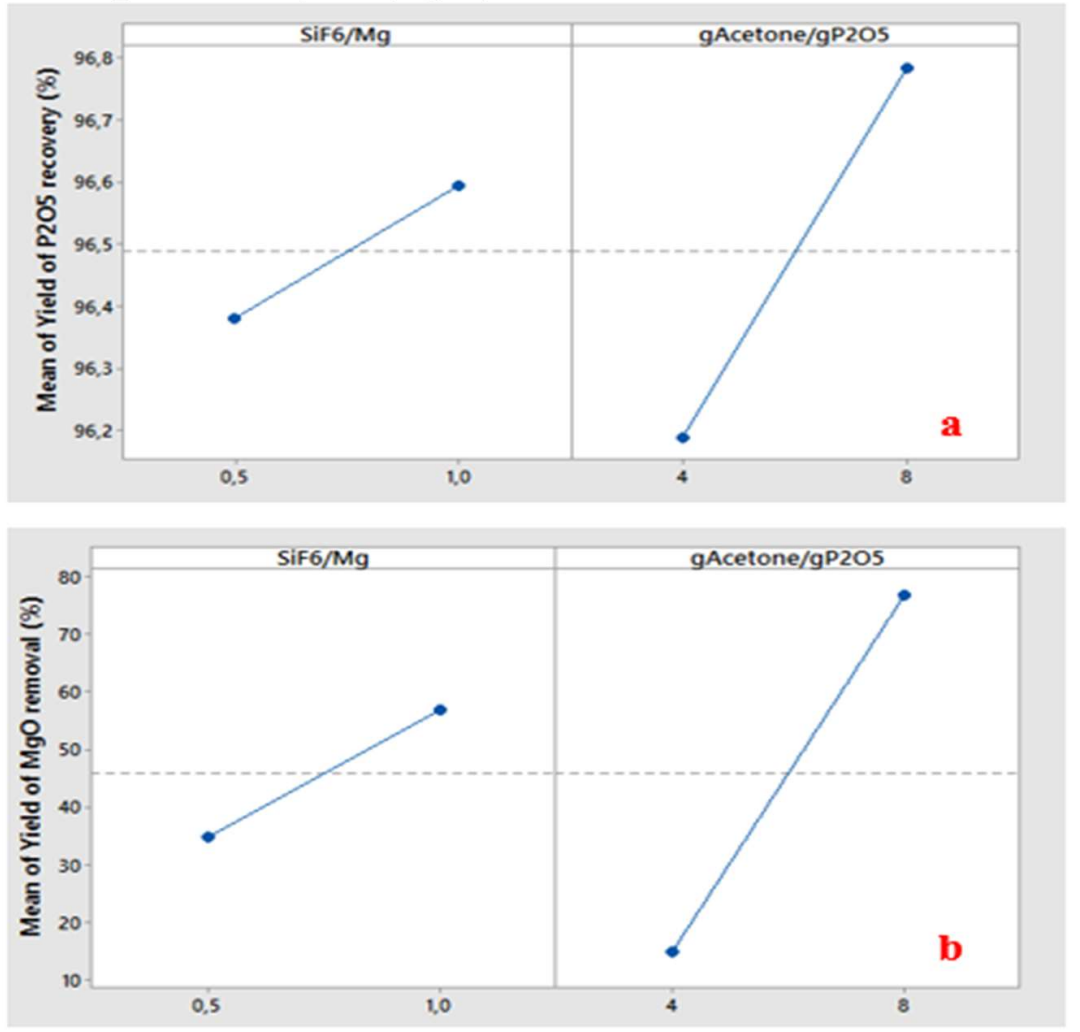

Fig.-1: Effect of the Amounts of $\mathrm{H}_{2} \mathrm{SiF}_{6}$ and Acetone on: (a) the $\mathrm{P}_{2} \mathrm{O}_{5}$ recovery yield; (b) $\mathrm{MgO}$ removal yield. 
RASĀYAN J. Chem.

Vol. 14 | No. 2 |836-843| April - June | 2021

According to Fig.-1, it can be seen that the effect of increasing the $\mathrm{SiF}_{6} / \mathrm{Mg}$ molar ratio is significantly positive, this increase makes it possible to further improve the precipitation yields. But a molar ratio of 1 is preferred, because one mole of magnesium requires one mole of $\mathrm{SiF}_{6}$ is check according to the following stoichiometric reaction:

$$
\mathrm{SiF}_{6}^{2-}+\mathrm{Mg}^{2+}+6 \mathrm{H}_{2} \mathrm{O} \rightarrow \mathrm{MgSiF}_{6}, 6 \mathrm{H}_{2} \mathrm{O}
$$

By exceeding this molar ratio, we will be in excess of $\mathrm{SiF}_{6}^{-2}$ ion, and therefore silica and fluorine becoming impurities in phosphoric acid. The effect of increasing the amount of acetone is an intense effect which has allowed to significantly increase the yields of $\mathrm{P}_{2} \mathrm{O}_{5}$ recovery and $\mathrm{MgO}$ removal. The presence of acetone in large quantities allows a significant release which facilitates the task of fluosilicic acid to easily precipitate magnesium. A precipitation performance diagram presented in Fig.-2 showing the $\mathrm{P}_{2} \mathrm{O}_{5}$ recovery and Magnesium removal yields as a function of the $\mathrm{SiF}_{6} / \mathrm{Mg}$ molar ratio and the amount of Acetone.

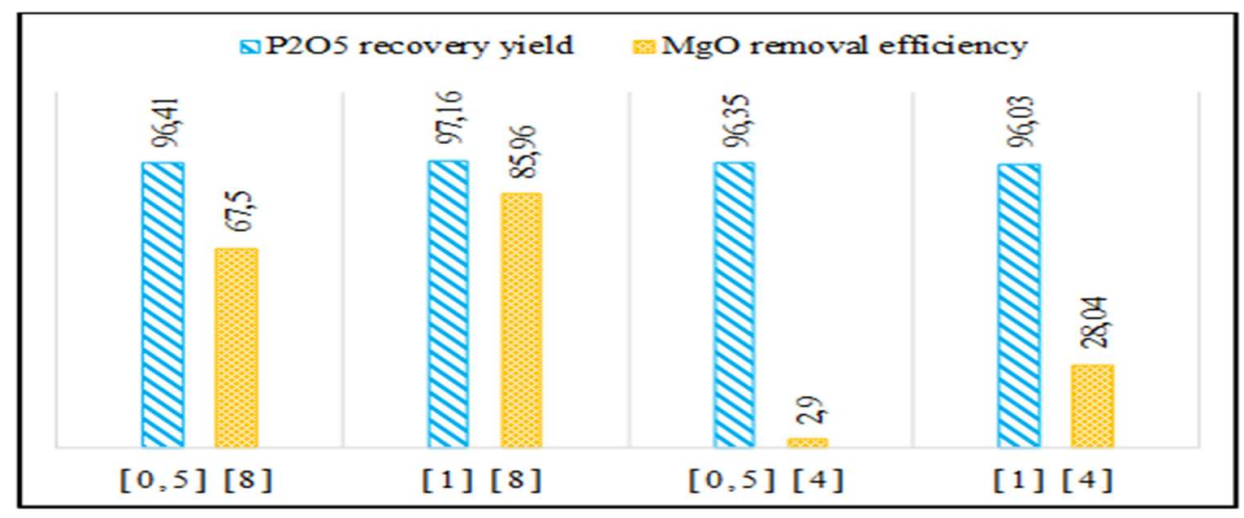

Fig.-2: Precipitation performance by addition of $\mathrm{H}_{2} \mathrm{SiF}_{6}$ and Acetone

From the two previous figures (Fig.-1 and Fig.-2), it is confirmed that the best performances of this magnesium precipitation process are recorded under the conditions of a molar ratio of 1 of $\mathrm{SiF}_{6} / \mathrm{Mg}$ and an amount of acetone of $8 \mathrm{~g}$ per $1 \mathrm{~g}$ of $\mathrm{P}_{2} \mathrm{O}_{5}$ initially present in phosphoric acid. Under these conditions, a $\mathrm{P}_{2} \mathrm{O}_{5}$ recovery yield of $97.16 \%$ and a magnesium removal yield of $85.96 \%$ are obtained.

A characterization in X-ray diffraction (XRD) of solid deposit precipitated under these optimal conditions present a crystalline product of Magnesium fluorosilicate hexahydrate $\left(\mathrm{MgSiF}_{6} .6 \mathrm{H}_{2} \mathrm{O}\right)$ as presented in Fig.3.

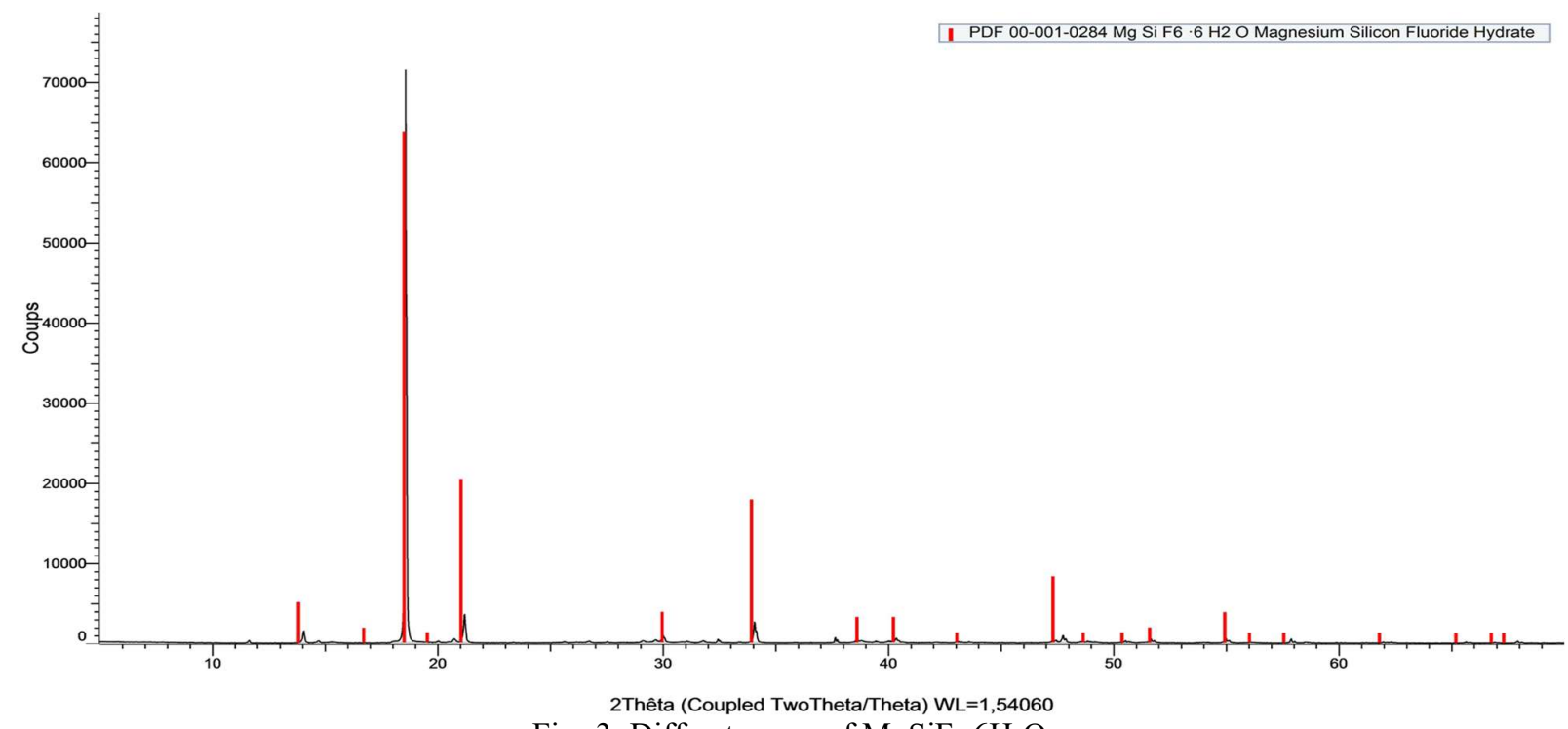

Fig.-3: Diffractogram of $\mathrm{MgSiF}_{6}, 6 \mathrm{H}_{2} \mathrm{O}$ 
RASĀYAN J. Chem.

Vol. 14 | No. 2 |836-843| April - June | 2021

\section{CONCLUSION}

In this work, by adding fluosilisic acid and acetone, we implemented a new process for removing magnesium from phosphoric acid $29 \% \mathrm{P}_{2} \mathrm{O}_{5}$ in order to avoid its negative impact on the production line downstream.

On the one hand, we recorded a $\mathrm{P}_{2} \mathrm{O}_{5}$ recovery yield of $97.16 \%$. The latter can be improved by optimizing the separation parameters by concentration of the phosphoric acid-acetone phases and by recovering a portion of soluble $\mathrm{P}_{2} \mathrm{O}_{5}$ by washing the solid cake with fluosilicic acid diluted to $20 \%$ prepared from a stock solution of $35 \% \mathrm{H}_{2} \mathrm{SiF}_{6}$. The washing filtrate recovered is a fluosilicic acid containing the soluble $\mathrm{P}_{2} \mathrm{O}_{5}$, it can be diluted to $10 \%$ of $\mathrm{H}_{2} \mathrm{SiF}_{6}$ and recycled to precipitation reactor. On the other hand, we obtained a magnesium elimination yield of $85.96 \%$ under the operating conditions of a molar ratio of 1 of $\mathrm{SiF}_{6} / \mathrm{Mg}$ and for a quantity of $8 \mathrm{~g}$ of acetone for $1 \mathrm{~g}$ of $\mathrm{P}_{2} \mathrm{O}_{5}$ initially present in phosphoric acid.

This process has several advantages. On the one hand, during this process, it is possible to use the fluosilicic acid produced in situ during the phosphoric acid concentration operations. On the other hand, the acetone used can be recycled into the process after a possible distillation operation. In addition, it should be noted that all the products and by-products of this process are easily separable by simple vacuum filtration. The solid phase of the hydrated magnesium fluorosilicate thus obtained can be purified and upgraded for possible industrial uses.

\section{REFERENCES}

1. P. Becker, Phosphates and Phosphoric Acid: Raw Materials, Technology and Economics of the Wet Processes, Marcel Deeker, Inc., New York (1983).

2. S. Van Der Sluis, Ph. D. Thesis, Delft University Press, TRdiss 1550, Delft, the Netherlands (1987).

3. J. $\mathrm{Yu}$ and D. Liu, Chemical Engineering Research and Design, 88(5-6), 712(2010), DOI: 10.1016/j.cherd.2009.11.008

4. Best Available Techniques for Pollution Prevention and Control in the European Fertilizer Industry, in: European Fertilizer Manufacturers' Association (eds), Production of Phosphoric Acid, England, Booklet No. 4 of 8. (2000).

5. A. Arlow, Ph. D. Thesis, Department of Chemical Engineering, University of Pretoria, Afrique du Sud (2003).

6. H. El-Shall, R. Stana, M. Qavi and L. Navajeevan, Effect of Rock Impurities as determined from Production Data, University of Florida, FIPR N $02-146-202$,Florida (2004).

7. Jacobs Engineering Group, Inc and A.N. Bauman, Defining the $\mathrm{MgO}$ problem and its economic impact on phosphoric acid production, FIPR $\mathrm{N}^{\circ}$ 01-102-112,Florida (1995).

8. A. Boukhsib, L. Khamar, M. S. Kadiri and L. Omari, International Journal of Engineering Sciences \& Research Technology, 8(7), 1(2019), DOI:10.5281/zenodo.3339301

9. L. Khamar, M. EL Guendouzia, M. Amalhay, M. Aboufaris El alaoui , A. Rifai , J. Faridi , M. Azaroual, Procedia Engineering, 83, 243(2014), DOI:10.1016/j.proeng.2014.09.045

10. Nilson J. Fernandes, Ph. D. Thesis, Faculty of Chemical Engineering, Federal University of Uberlândia, Brazil (2011).

11. A. Bendada, Ph. D. Thesis, Department of Industrial Chemistry, Faculty of Engineering Sciences, University of Constantine, Algeria (2005).

12. B. Khoualdia, M. Loungou and E. Elaloui, World Journal of Applied Chemistry, 3(4), 83(2018), DOI: $10.11648 /$ j.wjac.20180304.11

13. N. Boulkroune, Ph. D. Thesis, Department of Industrial Chemistry, Mentouri University, Constantine, Algeria (2012).

14. W. Mecibah, Ph. D. Thesis, Department of Chemistry, Badji Mokhtar University, Annaba, Algeria (2013).

15. D. Touaibia and H. Kerdjoudj, Journal of Applied Electrochemistry, 26(10), 1071(1996), DOI: $10.1007 / \mathrm{BF} 00242203$

16. M. B. C. Elleuch, M. B. Amor and G. Pourcelly, Separation and Purification Technology, 51(3), 285(2006), DOI:10.1016/j.seppur.2006.02.009

17. M. Campos Assunção, Ph. D. Thesis, Department of Analytical Chemistry, Pierre and Marie Curie University, Paris, France (2017). 
RASĀYAN J. Chem.

Vol. 14 | No. 2 |836-843| April - June | 2021

18. M. Campos Assuncao, G. Cote, M. Andre, H. Halleux, A. Chagnes, Royal Society of Chemistry Advances, 7(12), 6922 (2017), DOI:10.1039/C6RA25440C

19. W. P. Moore, R. R. Macgregor, and W. C. Sierichs, US Patent 3642439 (1972).

20. T. T. Leo and D. S. Bunin, US Patent 3379501 (1968).

21. H. E. Mills, US Patent 4136199 (1979).

22. K. L. Parks, K. D. Clevenger and D. P. Mcdonald, US Patent 4299804 (1981).

23. G. Bonel, J. C. Heughebaert, M. Chaabouni and H. Ayedi, US Patent 4692323 (1987).

24. D. Goldstein, US Patent 3819810 (1974).

25. J. F. McCullough and L.L. Frederick, US Patent 3975178 (1976).

26. F. Kabbaj, FR 2629812 (1989).

27. G. Nineuil, US Patent 4557915 (1985).

[RJC-6339/2020] 